\section{Edible earthworms in a food safety perspective: Preliminary data}

\author{
Cecilia Conti, ${ }^{1}$ Marta Castrica, ${ }^{2}$ \\ Claudia M. Balzaretti, ${ }^{2}$ \\ Doriana E.A. Tedesco $^{1}$
}

${ }^{1}$ Department of Environmental Science

and Policy (ESP), ${ }^{2}$ Department of

Health, Animal Science and Food Safety

(VESPA), University of Milan, Italy

\begin{abstract}
The world population and global food demand are increasing, particularly the demand for animal protein sources. At the same time, society produces large quantities of food waste. Sustainable solutions, to ensure enough food and to optimize the use of resources, are necessary. Earthworms grown on fruit and vegetable waste (FVW) can be a future alternative food source, contributing to waste disposal efficiency. They improve food sustainability under nutritional and environmental dimensions. These topics are included in the philosophy of the circular economy. Earthworms, characterized by a high percentage of proteins and minerals, are used as foods in some world countries, including China and the Philippines. In order to consider safety aspects of earthworms grown on FVW as food sources, this study evaluated the microbiological quality of FVW (i) used as growth substrate; fresh earthworms (ii) and earthworms' meal (iii) resulting from two technological processes (freeze-drying and drying). The efficiency of these technologies in reducing microbial contamination was evaluated. Microbiological analyses revealed the absence of Salmonella spp. and Listeria monocytogenes in $\mathrm{FVW}$, in fresh earthworms and in earthworms' meal. Fresh earthworms' results fell within the limits of acceptability, if related to the limit for minced meat (Interdepartmental Center for Research and Documentation on Food Safety). Both freeze-drying and drying step led to a further reduction of microbial contamination, confirming the importance of the processing methods. In conclusion, earthworms can represent an innovative biotechnological response to re-use FVW, a valuable food supplement of animal proteins and a strategy to improve food sustainability.
\end{abstract}

\section{Introduction}

The world population and global food demand are increasing, particularly the demand for animal protein sources, which are the most limiting and expensive in terms of resources (Alexandratos and Bruinsma, 2012; United Nations, 2017). At the same time, society produces large quantities of food waste. Globally 1.3 billion tons of food produced for human consumption is lost or wasted yearly. In particular, the fruit and vegetable sector generates large amounts of waste, especially in industrialized regions (FAO, 2011). All these food losses and waste bring to the squandering of economic, social and environmental resources that have been used to produce food uselessly. Considering the nutritional value, a lot of food ends its "life" with high nutritive elements in it. Finding sustainable and successful strategies against food wastage is necessary and a priority. These topics are included in the philosophy of the circular economy (European Commission, 2015).

The introduction of new foodstuffs is likely to be the right approach for sustainable living.

Earthworms grown on fruit and vegetable waste (FVW) contribute to waste disposal efficiency and are an interesting solution because transform FVW into valuable products: the vermicomposting, that can be sold as organic fertilizer, and the earthworms themselves that, thanks to their high protein content, can be a new food source. Earthworms are eaten in some areas of the world, including China and the Philippines (IFIS, 2009). Based on their nutrient content, earthworms Eisenia foetida are an excellent source of readily available protein and minerals in human diet and are included in the Dictionary of Food Science and Technology (IFIS, 2009). Several researches underlined the nutritional values of earthworms as food source (Anitha and Jayraaj, 2012; Cayot et al., 2009; Marconi et al., 2002; Paoletti et al., 2003; Sabine, 1983; Zhenjun and Jiang, 2017). According to the literature data, earthworms Eisenia foetida meal has high protein content in the range of 55 to $70 \%$ dry matter (Cayot et al., 2009; Edwards, 1985; Medina et al., 2003; Zhenjun et al., 1997; Zhenjun, 2005) and they are rich in the amino acids considered essential for humans (Zhenjun and Jiang, 2017).

Despite research on nutritional values of earthworms as food, the information concerning their food safety aspects remains limited.

In this study, an evaluation of microbial content of fresh and processed earthworms
Correspondence: Doriana E. A. Tedesco, Department of Environmental Science and Policy (ESP), Università degli Studi di Milano, Via Celoria 2, 20133 Milan, Italy.

Tel.: +39.02.50317906

E-mail: doriana.tedesco@unimi.it

Key words: Edible earthworms, Fruit and vegetable waste, Circular economy, Processing technologies, Microbiological analysis.

Contributions: the authors contributed equally.

Conflict of interest: the authors declare no potential conflict of interest.

Funding: This work was supported by Fondazione CARIPLO Integrated research on industrial biotechnologies 2015 (project 2015 0501): "Bioconversion of fruit and vegetable waste to earthworm meal as a novel food source".

Received for publication: 14 July 2018. Accepted for publication: 8 February 2019.

This work is licensed under a Creative Commons Attribution-NonCommercial 4.0 International License (CC BY-NC 4.0).

(C) Copyright C. Conti et al., 2019

Licensee PAGEPress, Italy

Italian Journal of Food Safety 2019; 8:7695

doi:10.4081/ijfs.2019.7695

was conducted. The aim of the study was to evaluate the microbiological safety of FVW (i) used as growth substrate, fresh earthworms (ii) and earthworms meal (iii) resulting from two technological transformation processes (freeze-drying and drying). Furthermore, the efficiency of these technologies in reducing microbial contamination was evaluated.

\section{Materials and Methods}

\section{FVW and earthworms samples}

Earthworms from the species of Eisenia foetida were reared in a farm located in the province of Lecco (Italy). The production system was an area of $34 \mathrm{~m}^{2}$. Growth substrate consisted of FVW and straw. FVW were provided by a fruit and vegetable producer of ready-to-eat products. In order to guarantee optimum growth conditions, the moisture, temperature and $\mathrm{pH}$ of the growth substrate were kept under control. The experiment lasted 3 months.

Samples of FVW and fresh earthworms Eisenia foetida for microbiological analyses 
were collected at the beginning of the rearing process (T1), in the middle (T2) at the end of it (T3).

\section{Cleaning procedure}

The first cleaning procedure consisted of a mechanically separation of earthworms from the growth substrate with the use of a trommel. Afterwards, they were repeatedly washed with running tap water and soaked, in order to remove the residual particles of waste and to clear their gut. Finally, after the excess water was removed with tissue paper, earthworms were packaged in plastic bags, weighed and stored at $-28^{\circ} \mathrm{C}$.

\section{Technological transformation processes}

Dry meal resulted from two technological transformation processes: freeze-drying and drying. In the first one, the samples were freeze-dried and ground with a mechanical crusher. In the second, dry meal was produced by drying them in an oven at $50^{\circ} \mathrm{C}$ and grinding. The two obtained dry meal were placed in vacuum plastic bags and stored at $-28^{\circ} \mathrm{C}$ until the subsequent analyses.

\section{Microbiological analyses}

The analyses focused on the microbiological quality of FVW growth substrate, fresh earthworms and earthworms meal, following the experimental design reported in Figure 1.

Considering that the microbiological content of earthworms depends on the growth substrate, for both FVW and earthworms samples the following parameters were investigated: Salmonella spp., Listeria monocytogenes, mesophilic aerobic bacteria, Enterobacteriaceae, E. coli, total coliforms bacteria, coagulase-positive
Staphylococci, Bacillus cereus and sulphitereducing clostridia.

An analytical unit (10 g) was aseptically taken from each sample, added to $90 \mathrm{~mL}$ of sterile solution $(0.85 \% \mathrm{NaCl}$ and $0.1 \%$ peptone), and homogenized in a stomacher and then serial 10-fold dilutions were prepared in a sterile saline solution. Salmonella spp. detection (analytical unit $25 \mathrm{~g}$ ) was carried out using UNI EN ISO 6579:2008 (ISO, 2008). The detection of $L$. monocytogenes (analytical unit $25 \mathrm{~g}$ ) was performed according to AFNOR BRD 07/4-09/98. Mesophilic aerobic bacteria and Enterobacteriaceae were enumerated using a Petrifilm (3M, St. Paul, Minnesota, USA), following the AFNOR 3M 01/1-09/89 and AFNOR 3M 01/06-09/97, respectively. Petrifilm plates were also used to determine E. coli, total coliforms bacteria and coagulase-positive Staphylococci in accordance

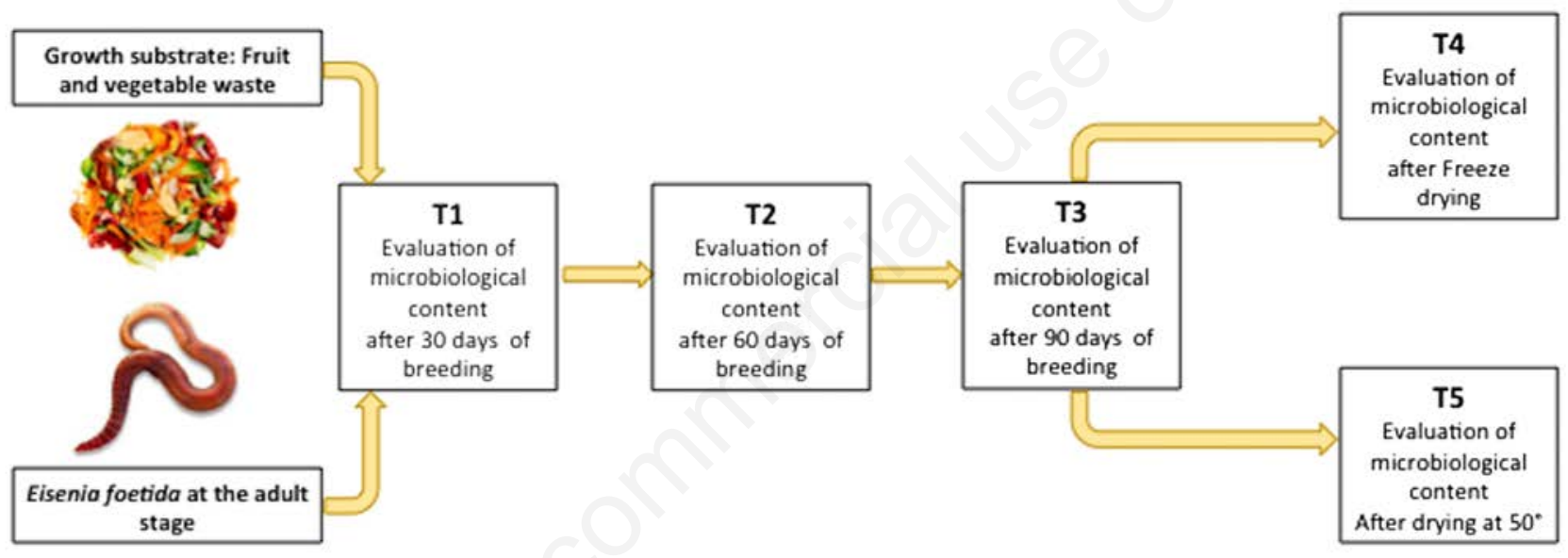

Figure 1. Experimental design.

Table 1. Standard CeIRSA guidelines for unprocessed raw fresh fruits and vegetables.

\begin{tabular}{|c|c|c|c|}
\hline \multirow[t]{2}{*}{ Bacteriological parameters } & \multicolumn{3}{|c|}{ Standard Ce.I.R.S.A guidelines (CFU/g) } \\
\hline & Satisfying & Acceptable & Unsatisfying \\
\hline Lysteria monocytogenes & Absent in $25 \mathrm{~g}$ & - & Presence in $25 \mathrm{~g}$ \\
\hline Salmonella spp. & Absent in $25 \mathrm{~g}$ & - & Presence in $25 \mathrm{~g}$ \\
\hline
\end{tabular}

Table 2. Standard CeIRSA guidelines for minced meat.

\begin{tabular}{lccc} 
Bacteriological parameters & Satisfying & $\begin{array}{c}\text { Ce.I.R.S.A guidelines (CFU/g) } \\
\text { Acceptable }\end{array}$ & $\begin{array}{c}\text { Unsatisfiying } \\
\text { Lysteria monocytogenes }\end{array}$ \\
Salmonella spp. & Absent in $25 \mathrm{~g}$ & & Presence in $25 \mathrm{~g}$ \\
\hline Mesophilic aerobic bacteria & Absent in $25 \mathrm{~g}$ & Presence in $25 \mathrm{~g}$ \\
Enterobacteriaceae & $<5 \times 10^{5}$ & $5 \times 10^{5} \leq \mathrm{x}<5 \times 10^{6}$ & $\geq 5 \times 10^{6}$ \\
\hline E. coli & $<10^{2}$ & $10^{2} \leq \mathrm{x}<10^{3}$ & $\geq 10^{3}$ \\
Sulphite-reducing clostridia & $<5 \times 10$ & $5 \times 10 \leq x 5<10^{2}$ & $\geq 5 \times 10^{2}$ \\
\hline
\end{tabular}


with the following methods: AFNOR $3 \mathrm{M}$ 01/08-06/01, AFNOR 3M 01/2-09/89 and AFNOR 3M 01/ 9-04/03, respectively. Bacillus cereus count was enumerated according to UNI EN ISO 7932:2005 (UNI, 2005). The sulphite-reducing clostridia were determined on iron sulphite agar after incubation in aerobic atmosphere at $37^{\circ} \mathrm{C}$ \pm 1 for 24-48 hours.

\section{Safety and hygiene criteria}

The results were compared with the guidelines provided by Interdepartmental Center for Research and Documentation on Food Safety (CeIRSA). In particular, the results obtained from FVW samples were compared with the limits provided for unprocessed raw fresh fruits and vegetables category (Table 1), while fresh and processed earthworms results were compared to minced meat category (Table 2).

\section{Results}

\section{Growth substrate}

Microbiological content of FVW revealed the absence of Salmonella spp. and Listeria monocytogenes in all samples. The other microbiological parameters evaluated for FVW are shown in Table 3.

\section{Fresh earthworms and earthworms meal}

Microbiological content of fresh earthworms and earthworms meal (freeze-drying and drying) revealed the absence of Salmonella spp. and Listeria monocytogenes in all samples, conforming to the Regulation (EU) 2073/2005 on microbiological criteria for foodstuffs (European Commission, 2005). The results of the remaining microbiological parameters evaluated for fresh earthworms are shown in Table 4. In earthworms the microbiological contamination was reduced by the use of the two different technological drying processes for meal production.

\section{Discussion}

In compliance with the Regulation EC No 2073/2005 (European Commission, 2005), no Salmonella spp. and L. monocytogenes were detected in FVW (growth substrate), fresh earthworms and earthworms processed meal samples. The absence of Salmonella spp. and L. monocytogenes is a criterion for food safety.

The FVW used as growth substrate were comparable to CeIRSA standards for unprocessed raw fresh fruits and vegetables category (CeIRSA, 2013).

Fresh earthworms resulted acceptable for all the parameters considered, except for Enterobacteriaceae, concerning CeIRSA minced meat category. However, the application of freeze-drying (T4) and drying (T5) processes to earthworms showed a reduction of all microbial parameters considered by CeIRSA, and were comparable to satisfying category reported for minced meat (CeIRSA, 2013). This confirmed the importance of the treatments to reduce the bacterial contamination in different terrestrial invertebrates proposed as food, as reported by Caparros Megido et al. (2017) and Grabowsky et al. (2017).

\section{Conclusions}

Possible food safety hazards associated with the use of novel proteins in food applications need to be prevented, following the European Union rules for animal deriving products. These hazards are associated to the rearing conditions (feed and environment) and the subsequent food technological process.

This study presented a general assessment of the microbiological evaluation on earthworms if they will be reared for food purposes. The research evidenced that earthworms meal could be a safe food for microbiological criteria. Furthermore, the results underlined the importance of the

Table 3. Microbiological results of FVW growth substrate.

\begin{tabular}{|c|c|c|c|}
\hline \multirow[t]{2}{*}{ Bacteriological parameters } & \multicolumn{3}{|c|}{ Microbial counts (CFU/g)a } \\
\hline & $\mathrm{T} 1$ (30 d) & $\mathrm{T} 2(60 \mathrm{~d})$ & T3 $(90 \mathrm{~d})$ \\
\hline Mesophilic aerobic bacteria & $10^{6}-10^{7}$ & $10^{5}-10^{6}$ & $10^{5}-10^{6}$ \\
\hline Enterobacteriaceae & $10^{5}-10^{6}$ & $10^{4}-10^{5}$ & $10^{3}-10^{4}$ \\
\hline E. coli & $10^{3}-10^{4}$ & $10^{3}-10^{4}$ & $<10$ \\
\hline Coliforms bacteria & $10^{6}-10^{7}$ & $10^{6}-10^{7}$ & $10^{5}-10^{6}$ \\
\hline Coagulase-positive Staphylococci & $<10$ & $<10$ & $<10$ \\
\hline Bacillus cereus & $10^{4}-10^{5}$ & $10^{4}-10^{5}$ & $10^{5}-10^{6}$ \\
\hline Sulphite-reducing clostridia & $10^{3}-10^{4}$ & $10^{2}-10^{3}$ & $<10$ \\
\hline
\end{tabular}

aThe results are expressed as range.

Table 4. Microbiological results of fresh earthworms.

\begin{tabular}{|c|c|c|c|}
\hline \multirow[t]{2}{*}{ Bacteriological parameters } & \multicolumn{3}{|c|}{ Microbial counts (CFU/g)a } \\
\hline & T1 (30 d) & $\mathrm{T} 2(60 \mathrm{~d})$ & T3 $(90 \mathrm{~d})$ \\
\hline Mesophilic aerobic bacteria & $10^{5}-10^{6}$ & $10^{4}-10^{5}$ & $10^{4}-10^{5}$ \\
\hline Enterobacteriaceae & $10^{5}-10^{6}$ & $10^{5}-10^{6}$ & $10^{3}-10^{4}$ \\
\hline E. coli & $10^{3}-10^{4}$ & $<10$ & $<10$ \\
\hline Coliforms bacteria & $10^{5}-10^{6}$ & $10^{4}-10^{5}$ & $10^{3}-10^{4}$ \\
\hline Coagulase-positive Staphylococci & $<10$ & $<10$ & $<10$ \\
\hline Bacillus cereus & $10^{3}-10^{4}$ & $10^{2}-10^{3}$ & $10^{2-10^{3}}$ \\
\hline Sulphite reducing clostridia & $10^{3}-10^{4}$ & $10^{3}-10^{4}$ & $<10$ \\
\hline
\end{tabular}

aThe results are expressed as range. 
processing methods (freeze-drying and drying) in the reduction of microbial contamination. As in other edible terrestrial invertebrates production, proper technological processing, packaging and storage conditions need to be considered in order to prevent the microbial contamination.

The next step to ensure safer products for consumers should be the establishment of specific guidelines for the production and commercialization of earthworms if they will be reared for human consumption.

\section{References}

Alexandratos N, Bruinsma J, 2012. World agriculture towards 2030/2050: the 2012 revision. ESA Working paper No. 12-03. Rome, FAO.

Anitha J, Jayraaj IA, 2012. Nutritional and antioxidant evaluation of earthworm powder (Eudrillus euginae). IRJP 3:177-180.

Caparros Megido R, Desmedt S, Blecker C, Béra F, Haubruge É, Alabi T, Francis F, 2017. Microbiological load of edible insects found in Belgium. Insects 8:1-8.

Cayot N, Cayot P, Bou-Maroun E, Laboure H, Abad-Romero B, Pernin K, SellerAlvarez N, Hernandez AV, Marquez E, Medina AL, 2009. Physico-chemical characterisation of a non-conventional food protein source from earthworms and sensory impact in arepas. Int J Food Sci Technol 44:2303-13.
CeIRSA, 2013. Linee guida per l'analisi del rischio nel campo della microbiologia degli alimenti, Allegato B.

European Commission, 2005. Regulation of 15 November 2005 on microbiological criteria for foodstuffs, 2073/2005/EC. In Official Journal, L 338, 22/12/2005.

European Commission, 2015. Communication (COM) No 614 final from the Commission to the European Parliament, the Council, the European Economic and Social Committee and the Committee of the Regions. Closing the loop - An EU action plan for the Circular Economy, 614/2015/COM.

FAO, 2011. Global food losses and food waste - Extent, causes and prevention. Rome.

IFIS, 2009. Dictionary of Food Science and Technology. 2nd ed. Wiley-Blackwell.

Grabowski NT, Klein G, 2017. Microbiology of cooked and dried edible Mediterranean field crickets (Gryllus bimaculatus) and superworms (Zophobas atratus) submitted to four different heating treatments. Food Sci Technol Int 23:17-23.

ISO, 2008. Microbiology of food and animal feeding stuffs. Horizontal method for the detection of Salmonella spp. ISO Norm 6579:2008. International Standardization Organization ed., Geneva, Switzerland.

Marconi S, Manzi P, Piuoferratoz L, 2002. Nutritional Evaluation of Terrestrial Invertebrates as Traditional Food in
Amazonia. BIOTROPICA 34:273-80.

Paoletti MG, Buscardo E, VanderJagt DJ, Pastuszyn A, Pizzoferrato L, Huang YS, Chuang LT, Millson M, Cerda H, Torres F, Glew RH, 2003. Nutrient content of earthworms consumed by Ye'Kuana Amerindians of the Alto Orinoco of Venezuela. Proc R Soc Lond B 270:249-57.

Sabine JR, 1983. Earthworms as a source of food and drugs. In: Satchell JE, ed. Earthworm Ecology. Chapman and Hall, New York, NY, pp 285-296.

UNI, 2005. [Microbiologia di alimenti e mangimi per animali. Metodo orizzontale per la conta di Bacillus cereus presunto. Tecnica della conta delle colonie a $30^{\circ} \mathrm{C}$. [Regulation in Italian]. UNI Norm 7932:2005. Italian Unification Institute ed., Milan, Italy.

United Nations, 2017. The impact of population momentum on future population growth. Population Facts No. 2017/4.

Zhenjun S, 2005. Nutritive value of Earthworms. In: Einfield NH Ed. Ecological implication of Miniliveestock, Science Publisher, Inc. pp 491-236.

Zhenjun S, Jiang H, 2017. Nutritive Evaluation of Earthworms as Human Food. In Heimo Mikkola, eds. Future Foods. IntechOpen, pp 127-141.

Zhenjun S, Xianchun L, Lihui S, Chunyang S, 1997. Earthworm as a potential protein resource. Ecol Food Nutr 36:22136. 